PAPERS

\title{
The management of large congenital liver cysts
}

\author{
A. RASHED \\ F.R.C.S. \\ R. E. MAY \\ M.S., F.R.C.S. \\ R. C. N. Williamson \\ M.Chir. F.R.C.S. \\ Departments of Surgery, Frenchay Hospital and The Royal Infirmary, Bristol
}

\begin{abstract}
Summary
Congenital solitary cysts of the liver seldom exceed $10 \mathrm{~cm}$ in diameter. Four such cases were seen over a 5-year period in a city with a catchment population of about 800,000 . One of these cysts was asymptomatic, but the others were complicated by intracystic haemorrhage, probable perforation and cyst-enteric fistula. Pre-operative liver scans and findings at laparotomy indicated a different treatment in each case-observation, aspiration, enucleation and drainage.
\end{abstract}

\section{Introduction}

Congenital cystic disease of the liver is usually discovered incidentally at laparotomy or postmortem examination, and symptomatic cases are rare. Some 500 cases have been reported since Brodie described hepatic cyst in 1846 (Jones, Mountain and Warren, 1974; San Felippo, Beahrs and Weiland, 1974; Williamson, Ramus and Shorey, 1978). Polycystic disease may affect the liver with or without renal involvement (Jones et al., 1974), but solitary hepatic cysts seem to be about as common (Henson, Grey and Dockerty, 1956).

We report 4 patients with congenital hepatic cyst, each presenting to the Bristol Hospitals during the last 5 years. Accurate delineation of the cysts was facilitated by preoperative scanning (isotope, ultrasound, computed tomography (CT)) plus arteriography in one case.

\section{Case reports}

\section{Case 1}

A 76-year-old woman was admitted with a 3-day history of central abdominal pain, radiating to the right side and back and accompanied by vomiting. Mild pyrexia and right hypochondrial tenderness suggested the diagnosis of acute cholecystitis, and anc intravenous cholangiogram showed several calculi in the gall-bladder. The white cell count $\left(10.3 \times 10^{9} / 1\right)^{\circ}$ and serum alkaline phosphatase (128 iu./1:을 normal 20-95) were slightly elevated.

When her symptoms resolved, she was readmitted $\bar{\varnothing}$ 3 months later for elective cholecystectomy. At laparotomy gallstones were confirmed, but in addi- $\frac{\mathbb{S}}{3}$ tion a large solitary cyst (greater than $10 \mathrm{~cm}_{\Phi}$ diameter) was found arising from the superior surface of the right lobe of the liver. An operatioe cholangiogram was normal, there being no commin: nication between the duct system and the liver cyst. The gall-bladder was removed but the cyst was left alone.

Subsequent serological tests excluded hydatid disease and amoebic infection. Ultrasound and $\mathrm{CT}_{\Omega}^{\Phi}$ scans confirmed that this was a solitary cyst of the $\vec{F}$ liver (Fig. 1). The patient made an uneventful? recovery and remains free of symptoms 15 months after the operation.

\section{Case 2}

A 72-year-old woman presented with a similar $3-\frac{3}{3}$ day history of pain in the right upper abdominalo quadrant. Three years earlier she had undergone 3 Patey mastectomy for Stage I intraduct carcinoma ofo the right breast. A smooth and non-tender hepatomegaly was noted on examination, and chest X-rayo showed elevation of the right hemidiaphragm. Liver function tests were normal apart from a minimal 0 increase in serum alkaline phosphatase (99 iu./1). N Technetium scans of the liver showed an enormous $\mathrm{CU}_{\mathrm{J}}$ defect occupying nearly all the right lobe, with $a_{\sigma}$ second and smaller defect near the lower margin of ${ }_{0}$ the left lobe. Ultrasonography confirmed that the $\frac{O}{\mathbb{D}}$ right hepatic mass measured $10 \times 8.5 \mathrm{~cm}$ and was transonic. A liver abscess was suspected.

Early laparotomy was performed. The liver was 


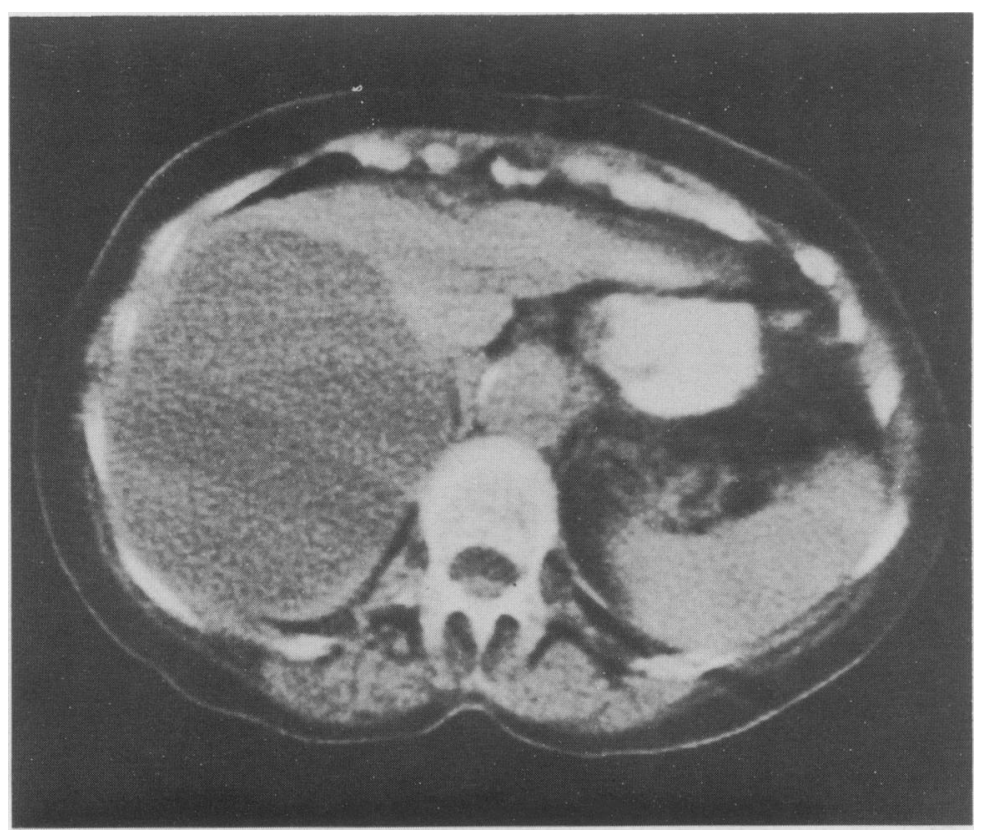

FIG. 1. Case 1. CT scan demonstrating a large cyst in the right hepatic lobe in a women of 76 . Aortic calcification is seen.

expanded by a cystic mass in the posterolateral portion of the right lobe, from which 2 litres of turbid fluid were aspirated. In addition, there were 6 small cystic lesions on the surface of this lobe, and one of these was excised for histological examination. The cyst lining comprised a single layer of cuboidal epithelium supported by a thin fibrous sheath. There was no inflammatory cell reaction, and the adjacent liver appeared normal. Cytological examination of the evacuated fluid showed scattered lymphocytes and polymorphs.

There were no postoperative problems, and 6 months later the liver was barely palpable. After one year the patient developed right subcostal pain on inspiration and 3-finger hepatomegaly was noted again. Needle aspiration of the liver under local anaesthetic retrieved $150 \mathrm{ml}$ of thick, dark fluid. One year later CT scan showed an enormous cyst virtually replacing the right hepatic lobe, and several satellite cysts were seen in the left lobe (Fig. 2). Subsequently the patient suffered renewed pain over the liver, which suddenly improved when she was bending down gardening. On palpating herself she realised that her liver swelling was diminished in size, presumably because the cyst had ruptured internally. She had no further symptoms, and no evidence of hepatomegaly was detected $3 \frac{1}{2}$ years after initial presentation.

\section{Case 3}

A 58-year-old man required emergency admission because of pain in the right lower chest and shoulder tip, which had started suddenly 10 days beforehand. The pain was aggravated by deep breathing and had gradually increased in severity. The only abnormal physical signs were diminished air entry at the right base and smooth hepatomegaly. Blood tests were essentially normal, though serum alkaline phosphatase was marginally elevated (92 iu./1). Ultrasound scanning (Fig. 3) and selective hepatic angiography revealed the presence of a $13 \mathrm{~cm}$ cyst in the right hepatic lobe (Fig. 4). Since the patient owned 2 dogs and some sheep the possibility of hydatid disease was raised, but the complement fixation test was negative.

The abdomen was explored through an upper midline incision, which was subsequently extended into the right chest along the bed of the sixth rib. There was an enormous cyst arising from the upper part of the right lobe of the liver. Superiorly the cyst was discoloured and adherent to the diaphragm. About 2 litres of brown fluid aspirated from the cyst had the appearances of altered blood. Some of the fluid was immediately examined, and parasitic infection was excluded. The recent haemorrhage into the cyst had resulted in infarction of its wall, together with the adjacent rim of liver tissue immediately 


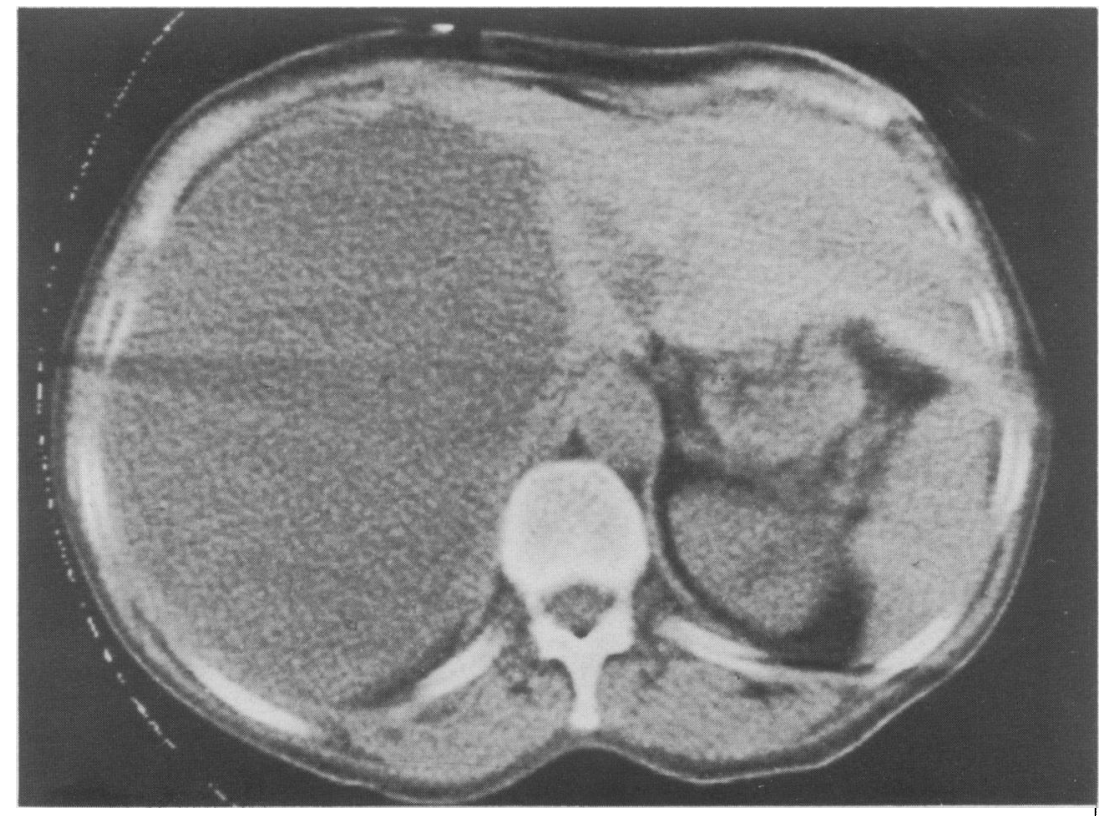

FIG. 2. Case 2. CT scan demonstrating a large cyst in the right lobe and a smaller cyst in the left lobe of the liver.

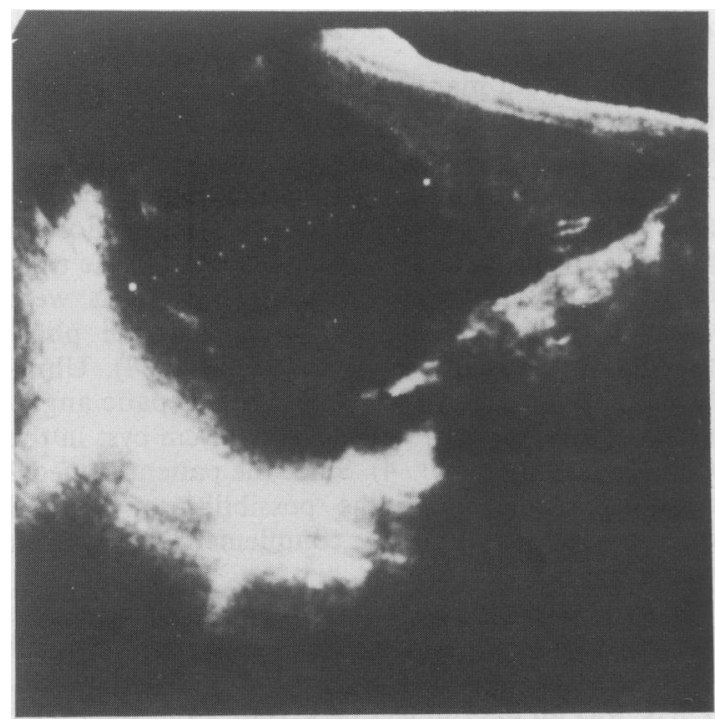

FIG. 3. Case 3. Ultrasound scan showing a $13-\mathrm{cm}$-diameter cyst in the right hepatic lobe.

below the diaphragm. The entire cyst was carefully enucleated from its bed within the liver. No major blood vessels were encountered, but one small bileduct required ligation. The postoperative course was uneventful. Histological examination again showed a simple non-neoplastic cyst, lined in part witho cuboidal epithelium.

\section{Case 4}

A housewife aged 49 developed a smooth swelling in the right subcostal region, $10 \mathrm{~cm}$ in diameter and increasing in size over the previous 9 months. Serum levels of alkaline phosphatase and transaminase were 3 persistently elevated, but serological tests for hydatidodisease were negative. Ultrasound and isotope scans 3 . showed a transonic mass in the medial part of the right hepatic lobe, which proved to be a solitary cyst at operation. After $1200 \mathrm{ml}$ of grey fluid had beeno aspirated, the cyst was opened inferiorly. The inci sion entered the common hepatic duct which waso intimately adherent to the cyst wall. The cyst was drained and a $T$-tube was left in the biliary tree for $2{ }^{\circ}$ weeks.

The patient did well at first but later developed N recurrent cholangitis and gastric outlet obstruction. AD fistula between the cyst and the first part of the duodenum was delineated on barium meal examination and successfully closed at a second operation? The case is reported in greater detail elsewhere 0 (Williamson et ál., 1978). 

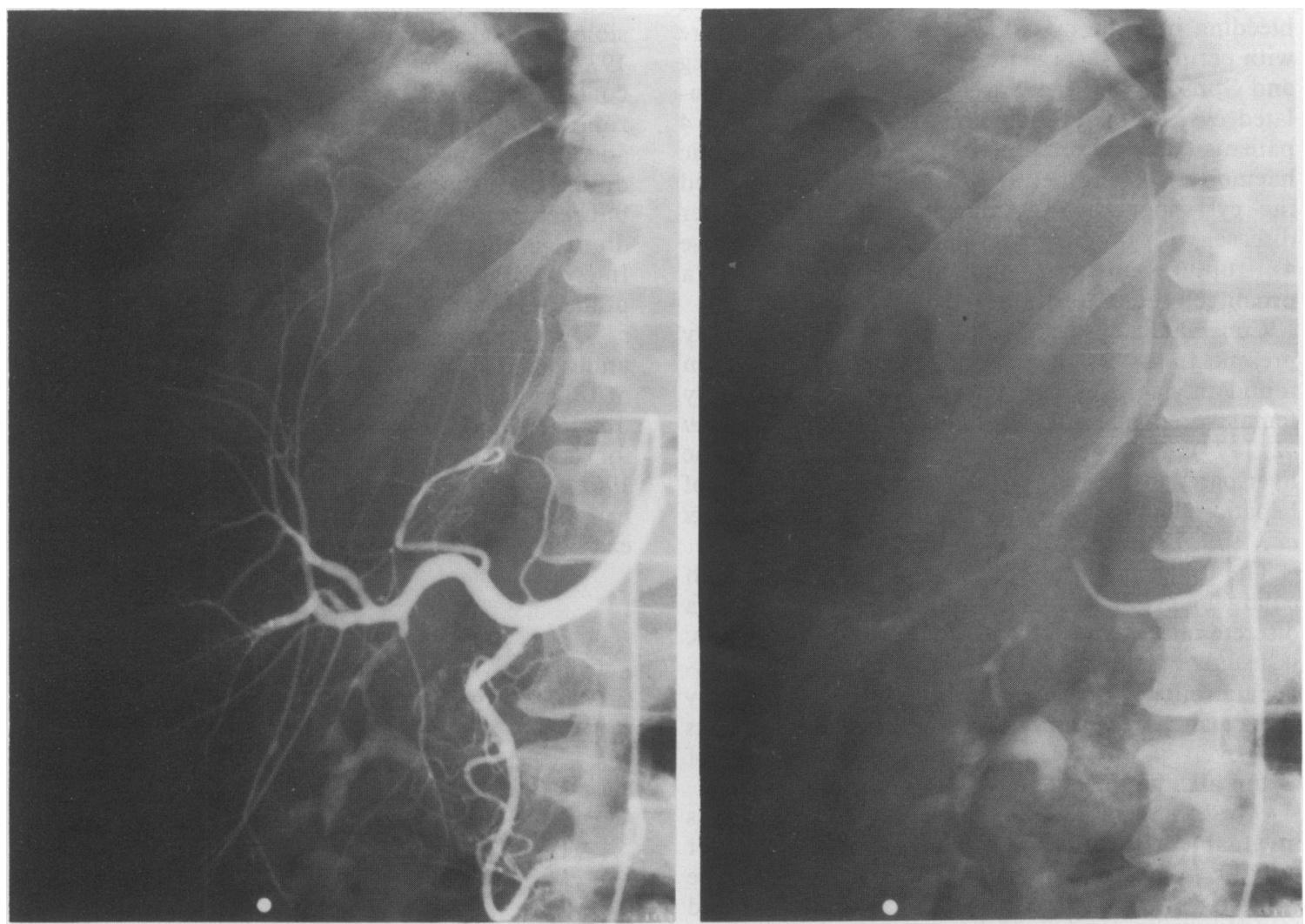

FIG. 4. Case 3. Selective hepatic arteriograms showing (A) vessels stretched around an avascular liver cyst, and (B) the outline of the cyst remaining as a 'halo' on a later film.

\section{Discussion}

\section{Classification and pathogenesis}

Cystic disease of the liver can be classified as parasitic and non-parasitic. Although hydatid disease predominates world-wide, in developed countries where Taenia echinococcus is uncommon, cysts are as likely to be congenital in origin (Williamson et al., 1978). Non-parasitic cysts are either neoplastic, traumatic or congenital. In neoplastic disease cysts arise as an integral part of the tumour, as with cystadenoma, or result from obstruction of the bile ducts (Gerber, 1954). Traumatic cysts follow parenchymal contusion when the overlying capsule is preserved (Robertson and Graham, 1933). Characteristically devoid of an epithelium (Hallenbeck and Tricke, 1950), they should be regarded as pseudocysts.

The presence of a cuboidal epithelium (as in Cases 2 and 3 ) and the frequency of communication with the biliary tree (25\% according to Longmire, Mandiola and Gordon, 1971 and Jones et al., 1974) support the generally-accepted theory that congenital cysts derive from aberrant bile ducts (Moschowitz, 1906). Most of these solitary cysts remain small and asymptomatic, but a few attain an enormous size, nearly filling the abdominal cavity (Burch and Jones, 1952). Diffuse polycystic disease of the liver is often associated with cystic disease of the kidney and sometimes the pancreas. A single gene is probably responsible for both congenital disorders (Dalgaard, 1957). Case 2 appears to illustrate an intermediate condition of multiple 'solitary' cysts without overt renal involvement.

\section{Clinical features and investigations}

Most patients with congenital liver cysts are unaware of the condition, but symptoms can arise either from complications or from pressure on the 
liver itself or surrounding viscera. There may be abdominal fullness and a dull ache in the epigastrium or right hypochondrium. Sudden severe pain suggests bleeding into the cyst (Grime et al., 1959), rupture with peritonitis (Morgenstern, 1959), infection (Greig and Stinson, 1961), or rarely torsion of a pedunculated cyst (Orr and Thurston, 1927). One of our 4 patients (Case 3 ) presented as a result of intracystic haemorrhage; another (Case 2) probably ruptured the cyst spontaneously during the course of her disease, with prompt relief of pain. In a third (Case 4), rupture into the duodenum gave rise to a prolonged internal fistula.

Congenital cystic disease of the liver usually presents in the fifth decade, although cysts have been found in neonates and pensioners. The customary female preponderance (Manheimer, 1953; Jones et al., 1974) may reflect some hormonal influence on the liver parenchyma, akin to the apparent induction of hepatic adenomas by oral contraceptives (Rooks et al., 1979; Lambruschi and Rudolf, 1979).

The only common physical sign is a smooth enlargement of the liver, which may contain a discrete mass (as in Case 4). Jaundice is uncommon; it usually results from compression of the extrahepatic biliary system rather than liver insufficiency (Flagg and Robinson, 1967). None of our patients had overt jaundice, but in each case the level of serum alkaline phosphatase was slightly increased.

Ultrasonic examination of the upper abdomen is invaluable in determining whether a mass in the liver is cystic (transonic) or solid. CT scanning and isotope scanning were each used in 2 cases and showed hepatic filling defects. Selective angiography helped to localise the lesion in Case 3 and displayed the arterial supply before cystectomy.

\section{Treatment}

Expectant treatment seems sensible both for polycystic disease and for solitary congenital cysts in the absence of symptoms, especially in the elderly or infirm as in Case 1. Aspiration is appropriate for larger cysts that are encountered incidentally at operation (Longmire et al., 1971). A second (percutaneous) aspiration was successfully employed in Case 2 , but repeated needling must increase the risk of infection in the cyst cavity. Attempts to obliterate the cyst by injecting sclerosants, such as formalin (Rosenberg, 1956), seem ill-advised, because of the risk of damage to communicating bile ducts or functioning hepatic tissue.

Younger symptomatic patients require operative treatment (Warren and Polk, 1958; Grime et al., 1959; Clark et al., 1967). The location, extent and precise anatomical relationships of the cyst should be determined, and operative cystography or cholangio- graphy may be helpful (Jones et al., 1974). Complete excision by enucleation or by partial hepatic resec- $c$ tion is the treatment of choice, whenever feasible (Ameriks, Appleman and Frey, 1972; Russell, $\stackrel{\text { () }}{+}$ 1972; Williamson et al., 1978). Emptying the cyst? contents by needle aspiration assists hepatic mobili- $\underline{\bar{\sigma}}$ zation, but thoracolaparotomy was needed to ensure $\frac{\bar{\rho}}{\bar{C}}$ adequate access in Case 3. Partial excision or $\stackrel{\mathbb{}}{\varrho}$ drainage into the peritoneal cavity can be successful, but recurrence is quite likely (as in Case 4). External drainage should be performed for infected cysts. Internal drainage into a jejunal loop is more appro- $\vec{\omega}$ priate, however, if the cyst contains bile (Longmire et $\stackrel{\circ}{\circ}$ al., 1971); this procedure should probably have been 8 undertaken at the first laparotomy in Case 4, because 3 . of the intimate association of the cyst to the biliary or tree. Hepatic lobectomy has occasionally been used $\sigma$ for large complicated cysts (Minton and Kinsey, $\underset{\omega}{\infty}$ 1961). Lastly, it is important to recognize the rare of neoplastic cysts, since any procedure short of total excision will inevitably result in recurrence.

\section{References}

Ameriks, J., Appleman, H. \& Frey, C. (1972) Malignant nonparasitic cyst of the liver. Case report. Annals of Surgery, 176, 713. 은 BRODIE, B.C. (1846) Lectures illustrative of various subjects. Pathe logy and Surgery Lecture V, Longman, London.

BURCH, J.S. \& JONES, H.E. (1952) Large non-parasitic cyst of the N liver stimulating an ovarian cyst. American Journal of Obstetritas and Gynecology, 63, 441.

ClaRK, D.D., MARKS, C., BernhaRd, V.M. \& BUNKFeldT, T. (1967) Solitary hepatic cysts. Surgery, 61, 687.

DALGAARD, O.Z. (1957) Bilateral polycystic disease of the kidneys; a follow-up of two hundred and eighty-four patients and their $\frac{}{\mathbb{Q}}$ families. Acta medica scandinavica, 158, (Suppl. 328), 1.

FLAGG, R.S. \& ROBINSON, D.W. (1967) Solitary non-parasitic $\overrightarrow{\vec{\sigma}}$ hepatic cysts. Archives of Surgery, $95,964$.

GERBER, A. (1954) Retention cysts of the liver due to bile duct polyp. Annals of Surgery, 140, 906.

GREIG, G.W.V. \& STINSON, R. (1961) Solitary non-parasitic cysts of the liver. British Journal of Surgery, 48, 457.

GRIME, R.T., MOORE, T., Nicholson, A. \& Whitehead, R. (1959) Cystic haematomas and polycystic disease of the liver. British $\bar{\sigma}$ Journal of Surgery, 47, 307.

HALlENBECK, G.A. \& TRICKE, R.W. (1950) Traumatic bile cyst of the liver. Report of 2 cases. Proceedings of Staff Meetings of the $\frac{O}{3}$ Mayo Clinic, 25, 648.

HenSON, S.W. JR., Grey, H.K. \& Docherty, M.B. (1956) Benign 음 tumours of the liver. III. Solitary cysts. Surgery, Gynecology and Obstetrics, 103, 607.

Jones, W.L., MOUNTAIN, J.C. \& WarRen, K.W. (1974) Sympto- 을. matic non-parasitic cysts of the liver. British Journal of Surgery, N
61,118 .

LAMBRUSCHI, P.G. \& RUDOLF, L.E. (1979) Massive unifocal cyst of $\mathbf{N}$ the liver in a drug abuser. Annals of Surgery, 189, 39.

LONGMIRE, W.P. JR, MANDIOLA, S.A. \& GORDON, H.E. (1971) స Congenital cystic disease of the liver and biliary system. Annals of Surgery, 174, 711.

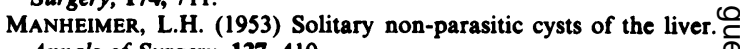
Annals of Surgery, 137, 410.

MinTON, J.P. \& KinSEY, D.L. (1961) Surgical management of a $\stackrel{\mathscr{+}}{+}$ recurrent solitary multilocular non-parasitic cyst of the liver. $\square$ American Journal of Surgery, 102, 710. 
MORGENSTERN, L. (1959) Rupture of solitary non-parasitic cysts of the liver. Annals of Surgery, 150, 167.

MoschowITZ, E. (1906) Non-parasitic cysts (congenital) of the liver with a study of aberrant bile ducts. American Journal of Science, 131, 674.

ORR, T.G. \& ThURSTON, J.A. (1927) Strangulated non-parasitic cysts of the liver. Annals of Surgery, 86, 901.

ROBERTSON, D.E. \& GRAHAM, R.R. (1933) Rupture of the liver without a tear of the capsule. Annals of Surgery, 98, 899.

ROOKS, J.B., ORY, H.W., ISHAK, K.G., STRAUSS, L.T., GREENSPAN, J.R., HILL, A.P. \& TYLER, C.W. (1979) Epidemiology of hepatocellular adenoma. The role of oral contraceptive use. Journal of the American Medical Association, 242, 644.
ROSENBERG, G.V. (1956) Solitary non-parasitic cysts of the liver. American Journal of Surgery, 91, 441.

RUSSELL, R.C.G. (1972) Ruptured solitary cysts of the liver. British Journal of Surgery, 59, 919.

San FelipPO, P.M., Beahrs, O.H. \& WeIland, L.H. (1974) Cystic disease of the liver. Annals of Surgery, 179, 922.

WARREN, K.W. \& POLK, R.C. (1958) Benign cysts of the liver and biliary tract. Surgical Clinics of North America, 38, 707.

WILliamson, R.C.N., RAMUS, N.I. \& SHOREY, B.A. (1978) Congenital solitary cysts of the liver and spleen. British Journal of Surgery, 65,871 . 